\title{
Doxa intelectual: conceito e emprego em um caso brasileiroI $^{I}$
}

\author{
Aline Rodrigues Chiaramonte*
}

Resumo: 0 presente artigo tem por objetivo apresentar o conceito de doxa intelectual situando sua concepção junto às análises de Pierre Bourdieu a respeito dos campos intelectual, filosófico e jornalístico. Na primeira parte, o texto se concentra sobre o trabalho de produção da doxa, em como se dá essa produção, e em como é feito o trabalho de imposição simbólica de uma visão do mundo social. Num segundo momento, apresentar-se-á o contexto de elaboração do conceito, ressaltando seu potencial explicativo para os objetos de pesquisa especificamente franceses. Para isso, serão utilizados os trabalhos de Bourdieu sobre os diversos campos de produção cultural (jornalístico, intelectual, filosófico e literário), entremeados com outros estudos realizados por pesquisadores ligados ao autor sobre os campos em questão. Nesse sentido, pretende-se, ainda, explorar as implicações que a noção traz para o nosso entendimento sobre o que seja um intelectual. Na porção final do artigo será dado o exemplo de um objeto de pesquisa que permitiu o emprego do conceito como ferramenta explicativa, demonstrando sua validade para a análise de problemas semelhantes em contexto nacional.

Palavras-chave: doxa intelectual, intelectuais, campo.

Não ler o que escrevo como se fosse um leitor. A menos que esse leitor trabalhasse, ele também, nos solilóquios do escuro irracional. Se este livro vier jamais a sair, que dele se afastem os profanos. Pois escrever é coisa sagrada, onde os infiéis não têm entrada. Estar fazendo de propósito um livro bem ruim para afastar os profanos que querem 'gostar'. Mas um pequeno grupo verá que esse 'gostar' é superficial e entrarão adentro do que verdadeiramente escrevo, e que não é 'ruim' nem é 'bom'.

(Clarice Lispector)

\section{Introdução}

Este texto nasceu da tentativa de entender um conceito elaborado num contexto intelectual diverso do brasileiro. Procurava-se, sobretudo, descobrir se uma noção estrangeira poderia ajudar a explicar um objeto construído tendo por referência os campos intelectual e jornalístico nacionais". Desse modo, foi feito um "tra-

\footnotetext{
${ }^{I}$ Agradeço aos pareceristas pelos comentários ao texto, com base nos quais reformulei partes consideráveis do artigo. Sou especialmente grata às professoras Ana Paula Hey e Sylvia Gemignani Garcia e aos integrantes do GPSECC (Grupo de Pesquisa em Sociologia da Educação, Cultura e Conhecimento), por terem lido a primeira versão do artigo e feito observações valiosíssimas, as quais ajudaram na reformulação do artigo.

*Graduanda em Ciências Sociais - USP.

${ }^{1} \mathrm{O}$ "trabalho genealógico" a ser referido decorreu da necessidade de fundamentar o resultado das reflexões iniciais desenvolvidas a partir da minha pesquisa de iniciação científica que, de modo geral, versa sobre o espaço
} 
balho genealógico", no qual se buscou descobrir os movimentos que resultaram no uso do conceito por Bourdieu e pelo grupo de pesquisadores ligados a ele.

No começo do artigo, o foco recai em apresentar a doxa intelectual, tornando visível seu modo de produção e circulação, isto é, o modo como certa configuração do campo intelectual francês favoreceu a construção de determinado tipo de produção simbólica híbrida, retrato da visão do mundo social que alguns de seus ocupantes veiculam por meio do acesso à mídia.

A segunda parte é dedicada a expor a gênese do conceito, demonstrando sua articulação com objetos de estudo, mais precisamente, com as análises centradas nos campos intelectual, filosófico e jornalístico francês. A doxa intelectual oferece, assim, um meio de explorarmos algumas propriedades da noção de "campo" elaborada e transformada gradualmente por Bourdieu ao longo de sua obra².

A partir das considerações tecidas, pretende-se expor os pressupostos que envolveram a criação do conceito de doxa intelectual, dando destaque para o que significa ser um intelectual de acordo com a acepção bourdieusiana.

Já no final do texto, volta-se às preocupações que orientaram a produção do artigo, demonstrando a maneira pela qual o conceito ajudou a entender a formação de determinado tipo de "saber" de senso comum que aos poucos vem substituindo as explicações mais "eruditas" sobre violência escolar.

\section{A doxa intelectual como produção híbrida}

Antes de tudo, faz-se necessário apresentar o conceito de doxa intelectual tal como foi inicialmente desenvolvido por Louis Pinto (2009):

A doxa intelectual, esse conjunto relativamente sistemático de palavras, de expressões, de slogans, de questões e de debates cujas evidências compartilhadas delimitam o pensável e tornam possível a comunicação, é o produto coletivo e anônimo das trocas que tendem a se instaurar entre jornalistas e intelectuais ou, mais precisamente, entre os mais intelectuais dos jornalistas e os mais jornalistas dos intelectuais, nos lugares neu-

social das representações construídas pela mídia escrita sobre violência escolar no Brasil, durante o período de 2000 a 2010. A análise de tal espaço revela como e porque certas maneiras de explicar a violência escolar prevaleceram sobre outras no período estudado, dando destaque para o papel da mídia e dos "porta-vozes" na produção da doxa dessa temática específica.

2 Por ora, cabe definir campo como: “[...] um campo de forças (há relações de forças num campo, a distribuição diferencial de forças) e um campo de lutas para transformar ou conservar a estrutura de distribuição de energia, de capital, de poder, e os lucros aferentes" (BOURDIEU, 1999, p. 7; tradução nossa). 
tros propícios à atenuação das diferenças e ao acúmulo de capitais relativamente heterogêneos (p. 6; tradução nossa) $)^{3}$.

A formulação sugere que nos concentremos na configuração atual do campo filosófico francês ${ }^{4}$, pois ela nos ajudará a entender posteriormente a dinâmica do campo intelectual. Gestada a partir dos anos 1960, sua principal característica é ser marcada por mudanças morfológicas, pelas "mudanças de número, de volume e de tamanho das audiências, do $\operatorname{corps}^{5}$, o aumento do corpo de professores, o fato de que lá onde havia um professor, agora há dez" (BouRdieu, 1999, p. 22; tradução nossa). Durante esse período, com o afluxo de estudantes de origens sociais até então excluídas do sistema de ensino ${ }^{6}$, cria-se a necessidade de aumentar o recrutamento de indivíduos para compor o corpo professoral. Se antes eram privilegiadas determinadas categorias - no caso da filosofia, estudantes da Escola Normal Superior, homens, parisienses - agora esse privilégio se vê ameaçado: "Quando não há mais normaliens agrégés homens, admitem-se os agrégés não-normaliens ou mulheres; e assim por diante" (BouRdIEU, 1999, p. 23; tradução nossa). Disso resulta uma série de medidas empreendidas pelo corpo professoral em defesa de seus privilégios. Há, assim, por exemplo, o aumento das distâncias entre os professores detentores dos cargos mais prestigiosos e o "baixo clero", formado pelos mestres-assistentes, mestres de conferência etc., que questionam cada vez mais as instâncias de consagração do corps, os concursos de cooptação e a Agrégation, por exemplo. Decorre desse "mecanismo de defesa" a formação de uma espécie de "intelligentsia sub-proletaróide", agentes passíveis de consumir (junto ao número crescente de estudantes em geral) e produ-

\footnotetext{
${ }^{3}$ Optou-se pela tradução das passagens em francês para melhor fluência do texto.

${ }^{4}$ A noção de doxa intelectual foi cunhada por Louis Pinto com base em suas pesquisas sobre o campo filosófico francês, por isso a escolha por retraçar em linhas gerais a história social desse campo. Cabe ressaltar aqui a centralidade que a filosofia desfrutava no campo acadêmico francês, fazendo com que a definição de intelectual passasse obrigatoriamente pelo campo filosófico. Pode-se citar aqui a figura de Sartre, que aliou à sua formação filosófica na Escola Normal Superior a vocação de escritor, intervindo enquanto intelectual no campo político com o respaldo da totalidade dos campos de produção cultural.

5 "Há um corps quando um conjunto de indivíduos é relativamente homogêneo do ponto de vista dos princípios de diferenciação dominantes num universo social considerado e unido por uma solidariedade fundada sobre a participação em comum no mesmo capital social e simbólico" (BouRdieu, 1999, p. 11; tradução nossa).

${ }^{6}$ Situação analisada por Bourdieu em seus trabalhos sobre o sistema de ensino. De uma forma embrionária em "A escola conservadora: as desigualdades frente à escola e à cultura" (1966) e, de forma mais desenvolvida, em "Os excluídos de interior" (1992). Disponíveis em Bourdieu (1998).
} 
zir obras de um novo tipo, transgressoras dos rótulos acadêmicos e das fronteiras entre as disciplinas.

Outro fator determinante que marca a configuração atual do campo filosófico francês - e que nos diz respeito mais diretamente - é o desenvolvimento das mídias, que inaugura um mercado para uma produção filosófica de feição midiática. 0 "novo filósofo" é formado pela e para a exposição na mídia, frequentador assíduo que é dos meios de comunicação (BourdiEu, 1997). Esse tema será desenvolvido mais adiante. Por ora, cabe pôr em relevo a estrutura bipolar (gestada desde os anos 1960) que compõe o campo filosófico atualmente. Por um lado, o polo do corpo de professores, formado de acordo com os cânones filosóficos nacionais. De outro, o polo midiático, introduzido pelo "equívoco estrutural no qual a vanguarda filosófica se viu do mesmo lado que os jornalistas na fase ascendente dos anos 1960" (PINTO, 1994, p. 30; tradução nossa).

Por certo, a estrutura observada é resultado de uma série de desenvolvimentos anteriores do campo filosófico ${ }^{7}$. Passando de corps a campo, o universo filosófico conheceu outras instâncias de consagração que não o julgamento pelos pares. A emergência de Sartre e suas atitudes heréticas de intelectual total que falava em nome de campos sociais até então separados - o campo acadêmico filosófico e o campo dos escritores - forneceram um repertório de papéis intelectuais a serem midiatizados pelos "novos filósofos", que deixam de lado aquilo que é mais importante do ponto de vista da consagração pelo corps: a obra.

As novas instâncias de consagração impostas pela mídia ao campo em questão vão desde a aparição constante nos jornais e revistas (os habitués das mídias ou, como os chama Serge Halimi (1998), os “intelectuais de corte”, profissionais supersolicitados que devem às relações de interconhecimento sua presença constante nos meios midiáticos), até a realização de enquetes sobre "Quem são os (as) três intelec-

\footnotetext{
${ }^{7}$ De acordo com Bourdieu (1999), antes do final do século XIX, a filosofia francesa era feita por não profissionais, matemáticos e politécnicos em sua maioria (Comte, por exemplo). Nos anos 1880, formou-se um corps de filósofos que lutaram para se diferenciar dos outros não profissionais por meio do ensino da disciplina e da concentração de esforços em torno do fortalecimento da História da Filosofia. Daí o estabelecimento de um conjunto de textos canônicos que constituem repertório obrigatório dos filósofos daquele país. Até os anos 1900, os filósofos funcionaram enquanto corps, impondo um alto direito de entrada àqueles que pretendiam participar da tradição filosófica. A partir dos anos 1900, começou a ser gestada a estrutura que, grosso modo, impera até hoje: de um lado, tem-se a filosofia acadêmica, ortodoxa, que funciona ainda como corps. De outro, os filósofos-jornalistas, heréticos e dissidentes.
} 
tuais vivos de língua francesa cujos escritos parecem exercer profundamente maior influência sobre a evolução das ideias, das letras, das artes, das ciências etc.?", cujo ranking, recheado de intelectuais midiáticos, reflete a composição arbitrária do júri, com a sobrerrepresentação de "juízes" oriundos da imprensa escrita (BouRDIEU, 1984). A imposição de outros sistemas de classificação que não o reconhecimento da obra pelos pares fez com que se instaurasse a heteronomia em um campo que até então era relativamente autônomo. Invertendo a lógica segundo a qual se formaram os campos de produção cultural (BouRDiEU, 2010), o polo midiático do campo filosófico francês introduziu a demanda social imediata como princípio avaliativo dos produtos filosóficos.

Às mudanças morfológicas e ao crescente papel assumido pela imprensa como instância de consagração, conjuga-se uma série de transformações na hierarquia das frações da classe dirigente e no campo das Grandes Escolas ${ }^{8}$. Pinto (2009) observou que a ascensão das Escolas ligadas à economia e à política teve, por contrapartida, 0 declínio do prestígio das Escolas mais antigas de orientação intelectual e científica. Essas últimas tiveram que redefinir seus programas, tendo por objetivo fornecer a seu público os valores de uma cultura voltada para a ação. Uma das retraduções dessa dinâmica no campo intelectual é uma inversão da hierarquia dos saberes; se antes eram valorizados os saberes desinteressados (filosofia, literatura, ciências sociais puras), hoje em dia são os saberes de dimensão temporal que "estão em alta" (Economia, Ciência Política, História política contemporânea, Sociologia dos problemas sociais).

No plano das obras, a produção dos "novos filósofos" apresenta diferenças tanto de natureza quanto de número. Contra a produção rotineira e ascética, de caráter, na maior parte das vezes, demonstrativo, produção laboriosa que leva tempo, cujos temas revelam o culto aos cânones da disciplina, os "novos filósofos" oferecem em seus livros anuais "pensamentos prontos", rápidos, dando uma demão de verniz intelectual sobre assuntos em evidência: o "fim da história", o "individualismo", a "pós-modernidade" etc.

No campo intelectual, essa postura se reflete na politização de todo e qualquer discurso:

\footnotetext{
${ }^{8}$ Ver Bourdieu (1989) La Noblesse d'État: grandes écoles et esprit de corps, um estudo específico sobre a particularidade do sistema francês de formação das elites.
} 
Eles [os "intelectuais de novo tipo"] falam quase sempre de política, mas de uma forma suficientemente elevada, para que seus comentários não pareçam uma simples reedição do que se diz na mídia [...]. Eles não se contentam em falar, eles agem quando a situação exige (PINTo, 2009, p. 14; tradução nossa).

A produção reflete a configuração do campo: assim como o campo filosófico, o campo intelectual francês também está sujeito à heteronomia. Na verdade, todos os campos de produção cultural estão sujeitos à heteronomia quando são obrigados a reconverter capitais que antes não eram válidos nesses universos ${ }^{9}$ - tem-se hoje, assim, a reconversão de capital social, da rede de relações que faz com que determinados "intelectuais" apareçam constantemente na mídia, em capital cultural, instaurando uma verdadeira situação de anomia nesses campos.

Explorando a ideia de "opinião pública" em seu livro A Distinção: crítica social do julgamento, Bourdieu nos expõe as peculiaridades que constituem o caráter do campo intelectual:

A ideia de 'opinião pública' [...] exprime, desde a origem, os interesses dos intelectuais, pequenos produtores independentes de opiniões, cujo papel se desenvolve paralelamente à constituição de um campo de produção especializado e de um mercado para os produtos culturais e, em seguida, de um subcampo especializado na produção das opiniões políticas (com a imprensa, os partidos e todas as instâncias representativas). $\mathrm{O}$ fato de produzir uma resposta a um questionário sobre política, como o fato de votar, ou, em outro nível de participação, de ler um jornal de opinião ou aderir a um partido, é um caso particular de encontro entre uma oferta e uma demanda: por um lado, o campo de produção ideológica, universo relativamente autônomo, em que se elaboram, na concorrência e no conflito, os instrumentos de pensamento do mundo social objetivamente disponíveis em determinado momento e em que, ao mesmo tempo, se define o campo do pensável politicamente ou, se quisermos, a problemática legítima; por outro, agentes sociais que ocupam posições diferentes no campo das relações de classe e definidos por uma competência política específica em maior ou menor grau [...] (BouRdieu, 2008, p. $372 ;)$.

Situado na intersecção entre o campo político e os campos de produção cultural, o campo intelectual participa do campo de produção ideológica. Espaço de lutas

\footnotetext{
9 “[...] sendo capital uma relação social, ou seja, uma energia social que existe e produz seus efeitos apenas no campo em que ela se produz e se reproduz, cada uma das propriedades associadas à classe recebe seu valor e sua eficácia das leis específicas de cada campo: na prática, ou seja, em um campo particular, nem sempre todas as propriedades incorporadas (disposições) ou objetivadas (bens econômicos ou culturais), associadas aos agentes, são eficientes simultaneamente; a lógica específica de cada campo determina aquelas que têm cotação nesse mercado, sendo pertinentes e eficientes no jogo considerado, além de funcionarem, na relação com este campo, como capital específico e, por conseguinte, como fator explicativo das práticas” (BouRdiEu, 2008, p. 107).
} 
entre diferentes grupos que disputam para impor sua visão como legítima do mundo social (sindicalistas, políticos, escritores, acadêmicos etc), o campo intelectual francês definiu sua autonomia somente quando, no fim do século XIX, com o processo de diferenciação entre tal campo e o político, os intelectuais afirmaram-se como autores capazes de impor a definição legítima das problemáticas sociais de maneira independente do poder político (SAPIRo, 2009). 0 caso Dreyfus ilustra bem essa posição, na medida em que os intelectuais intervieram enquanto tais na arena política, rejeitando as interpretações que o campo político lhes oferecia. Pode-se fornecer outro exemplo: o de quando Sartre engajou-se em defesa dos direitos humanos, apelando pelo apoio ao inimigo durante a guerra da Argélia. Ou seja, em nome de "direitos universais" e valores gerais concernentes a toda a humanidade, Sartre vai contra a "Razão do Estado" francês (BouRdiEU, 2010). Essa postura dos intelectuais faz parecer que nos encontramos diante de uma situação de concorrência advinda da total independência entre os campos político e intelectual. Entretanto, como propriedade geral de todo campo de produção cultural, tem-se que sua autonomia é sempre relativa. Assim como o grau de autonomia varia de um campo para outro, as diferentes posições no campo podem ser também mais ou menos autônomas. Por conseguinte, as transformações estruturais acima mencionadas contribuíram para a formação, no cerne do campo intelectual, de uma zona intermediária, onde "os mais intelectuais dos jornalistas" e "os mais jornalistas dos intelectuais" obtêm vantagens de sua posição híbrida, harmonizando a aparência intelectual de seus produtos com a constante visibilidade na mídia. Certa produção logra maior lucro simbólico por causar nos consumidores um erro de percepção, a alodoxia, que consiste em tomar uma coisa por outra, isto é, iludir-se quanto à autenticidade de determinado produto cultural, supondo que a notoriedade de determinados nomes substitui o julgamento da obra do produtor pelos pares (PinTo, 2009).

Até o momento, a análise da definição de doxa intelectual nos revelou que o campo intelectual, devido às suas próprias características - onde ele está situado, a fronteira que faz com outros campos etc -, está duplamente sujeito à heteronomia; quer pela invasão da mídia, quer pela injunção de determinados tópicos do campo político tidos como de tratamento obrigatório. Convém ressaltar que a produção desses "pensadores do novo" deve suas características à posição ocupada dentro da zona intermediária introduzida no campo intelectual. Louis Pinto (2009) distinguiu três regiões, dentro das quais se observa maior ou menor proximidade com os cam- 
pos político e midiático. Tem-se, por exemplo, na região direita, uma maior aproximação dos intelectuais com o campo político. Esse é o lugar dos think tanks e do indivíduo meio pensador meio agente de negócios. Seus estudos são feitos tendo em vista sua aplicabilidade à realidade, sendo suscetíveis de se tornarem reais. Nessa região, elabora-se a crítica ao que é velho, provinciano, nacional, ao direito adquirido, ao corporativismo, em oposição à exaltação da novidade, do dinamismo, do risco e da globalização. Aqui, se constrói uma representação do mundo social afeita aos interesses das classes dirigentes, sendo a maior parte de sua "população" politicamente de direita. A região central caracteriza-se pela diversidade ideológica, política e estratégica dos indivíduos e pela presença maciça dos intelectuais midiáticos. Se há alguns terrenos de desacordo, todavia, os agentes concordam no que concerne aos temas que mereçam ser relegados ao plano do arcaico: o marxismo, o estruturalismo e as ciências humanas em geral. Concordam, também, quanto aos novos objetos de estudo: a democracia, o cidadão, os direitos do homem, a liberdade, sempre pensando o mundo histórico de maneira "realista". A região esquerda é composta pelos intelectuais mais afastados do poder político. São radicais, em sua maior parte de esquerda, mas jamais chegam ao dogmatismo ou ao sectarismo. "Jovens hegelianos", os indivíduos dessa região tomam as revoluções no papel por revoluções na ordem mundial. São críticos de todos os pontos de vista, menos do deles próprios. Criticando a "velha esquerda", eles pregam uma "nova esquerda", tomando por base o "novo proletariado" e os "novos agentes da revolução".

Ainda que distintas em alguns pontos, essas regiões apresentam em comum o fato de recorrerem aos pares de oposição que constituem a doxa intelectual: novo/ velho, complexo/simples, nacional/global, reforma/conservação etc., suprimindo o debate típico dos campos culturais e científicos que contribui para a formação do repertório intelectual das diferentes disciplinas. A doxa contrasta com qualquer tipo de trabalho científico ${ }^{10}$ : se ela substitui o pensamento, uma vez que seu conteúdo é afastado daquilo que é passível de ser pensado e discutido, o discurso científico se opõe a ela como tese contestadora da ordem e do senso comum.

Esse fundo comum de classificações sociais é produto do que Pinto (2009) chamou por "lugares neutros", em clara alusão ao trabalho de Bourdieu e Boltanski

\footnotetext{
${ }^{10}$ Sobre o campo científico, cf. Bourdieu (2004).
} 
(2009) sobre a ideologia dominante. São espaços criados para a troca de ideias, de informações e de temas entre agentes sociais dos campos mais diversos. Assumem a forma de colóquios, reuniões e comissões. Jornais e revistas também podem servir como lugares neutros, pois permitem o "debate" entre detentores de capitais extremamente diversos. A produção simbólica resultante desses espaços, de aparente pluralidade e neutralidade, obscurece a lógica discursiva unitária que governa a produção dos lugares-comuns da doxa intelectual.

\section{O campo jornalístico e a doxa intelectual}

Muitos dos pressupostos da gênese do conceito de doxa intelectual entre Bourdieu e seus colaboradores já foram destacados na análise precedente, principalmente aqueles que se relacionam mais diretamente com as propriedades específicas do campo intelectual. Por isso, o texto se concentrará no exame das particularidades do campo jornalístico francês, ao passo que seu estudo favorece o entendimento de algumas das propriedades gerais inerentes aos campos de produção cultural.

É válido lembrar, nesse ponto, as considerações de Champagne (2007) a respeito do campo jornalístico; temos que ele é menos um campo específico ${ }^{11}$, no sentido de possuir uma legitimidade própria, um direito de entrada elevado e princípios explicativos internos (não recorrendo a outros universos), do que

um espaço de lutas que está na intersecção de três campos (no senso restrito) com princípios de legitimidade diferentes: o campo político, o campo econômico e o campo profissional (ou intelectual), porque a produção de informação deve ser composta levando-se em conta as leis próprias desses três campos. A 'informação' ou 'atualidade' comporta, com efeito, três dimensões indissociáveis: é um bem simbólico cuja produção supõe certo trabalho intelectual, mas que, além disso, deve ser economicamente rentável (isto é, vendável) e que, por outro lado, pode produzir objetivamente, querendo ou não, efeitos políticos de publicação (CHAMPAGNE, 2007, p. 51; tradução nossa).

Essa configuração torna-se mais compreensível quando passamos a considerar, em breves linhas, a história do jornalismo na França. Assim, na primeira metade

\footnotetext{
${ }^{11}$ Champagne toma como modelo de campo específico o campo científico, analisado por Bourdieu no artigo "Le champ scientifique" (1976). Ele é tratado como "idealtípico realizado (ou caso limite) da noção de campo (no senso restrito de microcosmo), isto é, de universo que, historicamente, tendo conquistado sua autonomia e achado seu princípio de legitimação próprio, sua inclinação natural seria a de funcionar como uma quase autarquia, ou de utilizar menos os outros campos em seu proveito" (ChAmPAGNE, 2007, p. 46).
} 
do século XIX, os termos "jornal”, “jornalista” e "imprensa escrita” eram subprodutos do campo político. Tratava-se de uma imprensa de opinião, direcionada às elites. Já na segunda metade desse século, desenvolve-se a imprensa de grande tiragem, organizada de forma industrial, subordinada à publicidade e à lógica econômica, cujas publicações se restringem a folhetins e artigos mais ajustados ao gosto do grande público. Assim, no final do século XIX tem-se a oposição entre a imprensa dita "séria", política, burguesa e de baixa tiragem, e a imprensa "sensacionalista", popular e de grande tiragem. Oposição essa que se complica com o aparecimento de um terceiro ator, o mundo intelectual, que impôs suas exigências próprias, de rigor intelectual e defesa da verdade (cujo modelo por excelência é o "J'accuse" de Zola), ajudando na elaboração dos códigos de deontologia da profissão. Dessa maneira, foi gestada a estrutura que se observa hoje em dia, sobre a qual Champagne nos chamou atenção: um "campo", cuja falsa autonomia resulta da instabilidade gerada na luta entre princípios de legitimidade diferentes.

Temos, dessa forma, que a influência do campo jornalístico, submetido como está às exigências do mercado - e tudo o que de mais nefasto isso possa acarretar: as notícias fáceis de serem assimiladas, os "fatos-ônibus", a concorrência pelo furo, o efeito de real que ele cria ao fazer existirem grupos e problemas, "o problema dos subúrbios" na França, por exemplo - ao entrar em contato com o campo intelectual acaba por impor a lógica da notoriedade e do índice de audiência a esse campo. Aqui, devemos ter em mente que, como todos os campos de produção cultural, o campo jornalístico também tem suas posições dominadas e dominantes, mais ou menos autônomas, caso estejam mais próximas do polo intelectual ou do campo político e econômico. Isso é válido tanto para os agentes quanto para os órgãos de difusão. Sendo o campo jornalístico também um espaço de produção cultural, a lógica de apreciação pelos pares apareceria como "restrições e controles cruzados, cujo respeito funda as reputações de honorabilidade" (Bourdieu, 1997, p. 105). 0 que se observa, porém, é o contrário: os jornalistas não estão sujeitos a nenhuma sanção pelos pares, sendo critérios puramente econômicos que orientam o julgamento dos produtos jornalísticos.

Os "efeitos de intrusão" de um campo no outro, no nível individual, tomam a forma de um acordo entre a posição ocupada pelos jornalistas no interior dos campos de produção cultural e o poder único que a conjuntura lhes proporciona: apesar de ocuparem uma posição dominada, eles detêm o monopólio de difusão dos 
produtos culturais em uma sociedade onde os indivíduos cada vez mais recorrem aos meios de comunicação como maneira de informar-se e de conhecer o mundo (Bourdieu, 1997). Nos campos de produção cultural, essa influência se traduz através da intervenção de agentes menos dotados de capital cultural, situados nos pólos mais heterônomos desses campos, os "jornalistas-intelectuais" ou "intelectuais-jornalistas", os doxósofos ${ }^{12}$, que, segundo Bourdieu (1998), não passam de técnicos da opinião que se creem cientistas.

\section{Modos de ser intelectual e a doxa intelectual}

Considerando que o volume do capital econômico cresce de maneira contínua, no mesmo momento que decresce o volume do capital cultural, quando se passa dos artistas para os empresários da indústria e do comércio, vê-se que a classe dominante organiza-se segundo uma estrutura em quiasma" (BOURDIEU, 2008, p. 108).

Os intelectuais diferenciam-se segundo sua posição no campo: autônomos ou heterônomos. No entanto, pela estrutura do espaço social ser organizada de tal forma que os intelectuais ocupam posições dominadas no interior da classe dominante - possuidores de um capital global no qual se observa maior volume de capital cultural, eles se distinguem da elite econômica que ocupa posição dominante pela razão de ser o capital econômico o princípio principal de estruturação do espaço social -, o modo como se relacionarão com o campo político é reflexo da busca por valorização de seu capital (SAPIRO, 2005).

Seguindo nessa chave, Sapiro (2005) propõe que analisemos os modos de intervenção política dos intelectuais franceses e sua evolução ao longo do século XX, colocando em relação o volume de capital simbólico detido pelo intelectual, a autonomia que ele possui em relação ao campo político e seu grau de especialização. A autora estabelece, assim, uma tipologia ${ }^{13}$, analisando sete modelos de intervenção intelectual, concentrando-se nas

\footnotetext{
${ }^{12}$ Bourdieu tratou de forma sistemática da questão da doxa em suas pesquisas sobre os intelectuais e sobre a mídia. Em artigo dos anos 1970, ele cunha o termo doxósofo, para se referir a certos especialistas que: "revelam, por uma inversão tipicamente socrática, sua ignorância do princípio da eficácia dessas perguntas, a saber: a inconsciência feliz da incompetência científica politicamente competente que faz com que o doxósofo, como teria dito Platão, especialista da doxa, opinião e aparência, sábio aparente e sábio de aparência, esteja fadado a dar aparências de ciência a um terreno em que as aparências sempre são a favor da aparência" (BouRdiEU, 1985, p. 154).

${ }^{13}$ Convém deixar claro que Sapiro não pretende estabelecer tipos fixos, mas sim modelos que se definem uns em relação aos outros.
} 
formas que se revestem as tomadas de posição do ponto de vista discursivo (do panfleto ao diagnóstico), as modalidades de intervenção (repertório de ação individual ou coletivo, tais como a petição, o manifesto, o agrupamento etc.), e os conteúdos das tomadas de posição (SAPIRo, 2005, p. 9-10; tradução nossa).

Desse modo, tem-se, em primeiro lugar, o intelectual crítico universalista, que retém grande quantidade de capital simbólico associado ao seu nome, orientando, por isso, grande parte das interpretações sobre o mundo. Ilustrado pelas figuras de Sartre e Zola, esse tipo de intelectual fala em nome dos valores e direitos intelectuais mais gerais - liberdade de expressão e justiça, os direitos humanos etc. Tal qual a figura do profeta analisada por Max Weber, o intelectual crítico universalista tem postura herética, correndo o risco de ser reprimido pelos poderes ortodoxos. Consoante a sua posição, seu modo de intervenção, pessoal e pontual, tem lugar nos momentos de crise.

O segundo modelo de intervenção intelectual na política refere-se ao guardião da ordem moralizadora, que pensa ser impossível o pensamento sem vinculação ao Estado ou à Igreja. Conforme sua concepção, a atividade intelectual deve estar subordinada à ordem social, contribuindo para mantê-la. Dentro do esquema quiasmático das classes dominantes, esses intelectuais ocupam posições mais próximas do polo econômico do que do cultural. Heterônomos, seu prestígio decorre mais da sua ligação com instituições de produção cultural e dos postos que ocupam no campo do poder do que do volume de capital simbólico acumulado. Veiculam seus produtos por meio da grande imprensa, de conferências e de ensaios. Suas objeções quanto aos intelectuais críticos tomam a forma de um anti-intelectualismo: rejeitando o pensamento "puro", eles exaltam o pensamento simples, defendendo-o como livre escolha intelectual.

No terreno das formas coletivas e autônomas de ação, Sapiro nos apresenta o modelo do agrupamento intelectual contestador e a vanguarda. Críticos e autônomos tanto quanto o intelectual crítico universalista, esses intelectuais diferem dele quanto ao volume de capital simbólico. Pobres nesse quesito, eles recorrem a formas de intervenção coletivas: os manifestos e as manifestações. Dominados no espaço das classes dominantes, eles estão na melhor posição para oferecerem críticas à ordem social.

Os intelectuais de instituição (religiosos) e de organização política são heterônomos no sentido de que suas pautas são orientadas por poderes externos ao campo 
intelectual. Por querer conciliar contrários, a saber, as posturas de militante e de intelectual, sua trajetória caracteriza-se pelas tentativas de adquirir autonomia no seio de uma instituição.

Continuando nos modelos de intervenção que se caracterizam pela heteronomia, tem-se o especialista consultado pelos dirigentes, ou expert ${ }^{14}$, que age politicamente salvaguardado por uma série de saberes e competências "neutras" garantidas pelo Estado (a estatística, por exemplo). Esse reconhecimento converte-se em serviço e as políticas públicas ganham respaldo científico.

Contra os experts, formou-se, na França, a forma especializada do intelectual crítico, o "intelectual específico", cujas figuras representativas são Foucault e Bourdieu. Recusando a ligação das ciências sociais com o poder político e econômico, os intelectuais específicos empenham-se em contestar o pensamento pronto e as ideias de senso comum. Baseiam sua forma de ação sobre o conhecimento acumulado da disciplina a partir da qual falam, contribuindo, desse modo, para desenvolvê-la. Sua postura rejeita qualquer tipo de profetismo do tipo sartriano, sendo o privilégio simbólico que sua especialidade lhes concede utilizado em favor dos dominados, dos que "não têm voz".

Por fim, tem-se o grupo contestatório especializado ou "intelectual coletivo". Herdeiros de Foucault, os intelectuais que se propõem a agir coletivamente também se baseiam em um tipo de saber específico, especializado. 0 acúmulo de competências (de diferentes disciplinas ou na mesma disciplina) lhes permite recusar o modelo do expert, sujeito que, dentre outros, trouxe a heteronomia para o campo intelectual francês.

O acima exposto permite aproximarmos os doxósofos dos intelectuais experts, cuja produção híbrida, mesmo em sua faceta midiática, apresenta um ranço político. Longe da produção autônoma dos intelectuais críticos universalistas, das vanguardas e dos intelectuais específicos, coletivos ou individuais, seus saberes refletem a ambição daqueles que, ocupando uma posição dominada no campo intelectual, procuram reconverter capitais valorizados em outros campos em capital cultural. Convém salientar que apesar de suas produções estarem orientadas por uma demanda externa, suas obras não são mera reprodução das temáticas que o campo do poder

\footnotetext{
${ }^{14}$ Sobre os experts, ver Dezalay e Garth (2000).
} 
lhes impõe. A noção de campo nos informa que não devemos incorrer no erro de curto-circuito, que consiste em estabelecer uma relação direta entre o produto cultural e o contexto em que é produzido. Tampouco devemos nos concentrar apenas na obra e a analisarmos internamente. Como universo intermediário, o campo refrata as problemáticas externas que se inserem em seu meio. Daí Bourdieu e Boltanski (2009) separarem os autores produtores da ideologia dominante que, apesar de sua aparente homogeneidade temática, diferenciam-se muito quanto à posição ocupada no campo intelectual. Os "mais intelectuais" se orientam, ainda que negativamente, pelos debates e problemas gerados por esse campo na medida em que aí são mais fortemente reconhecidos. Os dirigentes, contudo, não passam de meros reprodutores dos pensamentos dos intelectuais, adquiridos por meio da aprendizagem nas Escolas do poder francesas. Pinto (2009) também estabelece diferenças entre os "graus de sublimação" da doxa, que admite graus diferenciados de proximidade ou de distância para com as tomadas de posição político-ideológicas.

0 crítico da doxa é o intelectual que põe a descoberto seus fundamentos, investigando cientificamente como ela é produzida, quais são as formas de que ela se reveste e de que modo ela se espalha pelo mundo social. É o intelectual específico: individual, no caso de Bourdieu, cuja obra reflete a preocupação em contestar as noções de senso comum tanto dos leigos quanto dos próprios cientistas; coletivo, no caso de seus colaboradores, que se mobilizaram em torno dos movimentos sociais e do coletivo Raisons d'agir, que prolonga o legado da luta de Bourdieu contra o neoliberalismo.

\section{Um exemplo brasileiro: da violência escolar ao bullying}

Como foi dito no início do artigo, a preocupação central que orientou a realização da revisão bibliográfica a respeito da doxa intelectual era a questão da sua validade para análises de problemas semelhantes em contexto brasileiro. Por isso, nessa porção final do artigo será dado o exemplo de um caso em que o conceito atuou como ferramenta explicativa do deslocamento da temática da violência escolar para o bullying. Em outras palavras, a noção permitiu que fosse perscrutada a lógica das lutas e as estratégias por meio das quais, hoje em dia, somente o bullying ocupa tanto a pena dos pesquisadores quanto "a boca do povo".

O exemplo em questão foi retirado da minha pesquisa de iniciação científica, "Violência escolar: um problema social?", cujo ponto de partida consistiu na coleta e 
sistematização de todas as reportagens sobre violência escolar publicadas no período de 2000 a $2010^{15}$. Com isso, construiu-se um banco de dados que permitiu serem levadas a cabo três unidades de análise: na primeira, que é composta pelo conjunto de discursos sobre a violência escolar, buscou-se apurar quais representações foram elaboradas sobre o ponto em questão. Evidenciaram-se dois tipos principais, separados em eixos temáticos: no primeiro, como mote dominante, tem-se que a violência que atinge a escola vem de fora dela. 0 tráfico de drogas, os assaltos, as depredações, o vandalismo, as gangues etc., são meras transposições da violência que está no entorno da escola, que, por sua vez, é consequência de problemas estruturais da sociedade brasileira, a saber: a desigualdade social, a pobreza, a crise social etc. A atenção desse tipo de matéria se volta para a escola pública da periferia das grandes cidades, que deve ser alvo de aplicação de políticas públicas, tarefa que vai além da competência das escolas (e que está diretamente relacionada à aplicação de remédios para problemas estruturais) ${ }^{16}$.

O segundo tipo de representação (segundo eixo temático) sobre violência escolar apresenta-se numa roupagem temática oposta à primeira. Basicamente, reduz a violência ao indivíduo violento e às relações dele com os colegas. É o sujeito em sua individualidade que merece atenção, seu comportamento e conduta precisam ser geridos, medicalizados. As reportagens aqui se concentram sobre um único assunto, o bullying escolar.

De modo geral, a definição de bullying oferecida pelas reportagens coletadas gira em torno dos seguintes pontos: 1) envolve todo tipo de atitudes intencionais agressivas repetitivas (por exemplo, violência física, xingamentos e difamação pela internet - cyberbullying); 2) as agressões ocorrem sem motivo aparente; 3) causam danos físicos e/ou emocionais na vítima; 4) manifestam-se por atos executados por um ou mais alunos contra outro(s) envolvendo uma relação desigual de poder, que pode ser consequência da diferença de idade, tamanho, desenvolvimento físico etc.; 5) envolve preconceito por características físicas e/ou por traços de personalidade;

\footnotetext{
${ }^{15}$ Foram utilizadas matérias sobre violência escolar publicadas no Jornal Folha de S. Paulo e nas Revistas Veja e Nova Escola/Gestão Escolar. A escolha pelo jornal e pela revista Veja deu-se em função de sua ampla circulação e de sua linha editorial voltada para o grande público brasileiro. Optou-se pela inclusão da revista Nova Escola/ Gestão Escolar por sua especificidade na área educacional e por sua relativa circulação nesse meio.

${ }^{16}$ É patente a aproximação da temática do primeiro eixo com os assuntos que preocupam a produção acadêmica sobre violência escolar. Ver como exemplos Zaluar e Leal (2001) e Santos (2001).
} 
6) as atividades costumam ser admitidas por pais e professores como naturais, acabando por ignorá-las.

A primeira unidade de análise tornou possível a verificação do surgimento da temática do bullying no campo de estudos da violência escolar e de sua paulatina ascensão como representação principal. Isso só foi possível através da contabilização das matérias segundo os eixos temáticos e do cruzamento das informações obtidas com os anos nos quais as matérias foram veiculadas. Esse trabalho revelou a década de 2000 como "ponto de viragem", no qual a temática do primeiro eixo perde força em favorecimento do bullying, que vem ganhando centralidade ao longo dos anos.

Essa separação entre temas e períodos guiou a fase seguinte da pesquisa: a busca por informações a respeito dos agentes (segunda unidade de análise). No tocante ao perfil daqueles que se dedicam a representar a violência escolar enquanto matéria do primeiro eixo temático, tem-se que eles são, em sua maioria, vinculados às áreas da Educação e das Ciências Sociais. Receberam formação universitária nessas disciplinas e possuem um relativo volume de capital cultural acumulado, que pode ser aferido pela posse de títulos acadêmicos consagrados. Sua autoridade para falar no assunto advém da posição que ocupam no mundo universitário e pelos estudos que realizaram na área.

Aqueles que falam sobre o bullying nos jornais e revistas são oriundos dos campos os mais díspares. Em sua maior parte, são médicos, psicólogos e psicólogos sociais. Sendo o bullying um tema recente, mas que vem se consolidando como doxa, no campo dos produtores de discursos, convivem dois tipos de agentes: existem aqueles que assumem o papel de difusores do novo problema social, o que atesta a extensa produção de livros e artigos devidamente incluídos em seus currículos. Somado a isso, apresentam-se ainda como conferencistas e palestrantes. Eles podem atuar ainda como psicólogos clínicos e alguns estão ligados a atividades relativas à docência. Exercendo papel de reprodutores, estão os agentes mais "jovens", que lidam com o bullying na posição de estudantes de pós-graduação que se dedicam ao estudo do "fenômeno", ou como ativistas de ONGs que promovem campanhas de combate ao bullying e ao cyberbullying, enfim, são profissionais que atuam sobre o fenômeno já organizado, não questionando sua legitimidade. A posse de capitais os mais diversos e a intensa circulação nos meios midiáticos (sobretudo daqueles indivíduos que atuam como difusores) constituem o que é próprio a esse grupo. Sua aproximação com o universo acadêmico dá-se somente na medida em que há neces- 
sidade de recrutar agentes que trabalhem com a temática, inserindo-a no universo intelectual, o que dá aparência de certa legitimidade ao assunto em questão.

Na terceira unidade de análise - as instituições que dão legitimidade aos agentes e aos seus discursos -, observou-se que, ao contrário dos estudiosos que se dedicam às representações do primeiro eixo temático, cuja autoridade deriva, sobremaneira, de sua posição no campo acadêmico (pode ser ela dominada ou dominante), os produtores do "fenômeno bullying" firmaram-se enquanto representantes de ONGs e institutos dedicados à defesa dos direitos das crianças e dos adolescentes. A lógica que guia essas instituições e os agentes que atuam nelas e a partir delas ancora-se na crença de que a difusão de informações sobre o bullying pode servir para modificar as condutas e comportamentos agressivos. No limite, a mídia agiria como um elemento catalisador da função dessas ONGs e institutos, que trabalham como intermediários entre o conhecimento científico, com sua linguagem acadêmica, e a população.

0 aparecimento do bullying enquanto problema social ficou condicionado à realização de pesquisas que tiveram por objetivo fazer crer que, no Brasil, o bullying era um tipo de violência escolar real tão perigoso quanto outras violências causadas por fatores externos. A construção social do bullying demandou, além do mais, a formação de grupos de debates, conferências, cursos de pós-graduação etc., e, mais importante, a construção de categorias cognitivas, de um conjunto de referências por meio das quais pode haver debate de ideias e formação de saber.

A construção do campo de saberes sobre o bullying correlaciona-se com a fragilização da tese de que a violência escolar era causada por fatores estruturais inerentes à sociedade brasileira. 0 conjunto de problemáticas que representava a violência como efeito do impacto do social no destino do indivíduo, que prescrevia a gerência das situações de risco, de vulnerabilidade, foi aos poucos cedendo lugar para um apanhado de saberes que se centra na gestão dos indivíduos, de seus corpos, mentes e condutas.

Se os remédios para os problemas estruturais baseavam-se no diagnóstico proferido a partir da avaliação, do esquadrinhamento e do conhecimento das situações específicas, apoiando-se no que era "dado a ver", o conhecimento do indivíduo independe das particularidades do contexto em que está inserido. Os antídotos para o bullying podem ser tomados de outras realidades, não importa. 0 comportamen- 
to está inscrito no biológico, que é universal. Dessa forma, o "tratamento" para o bullying das escolas brasileiras pode ser o mesmo que o das escolas americanas, norueguesas etc.

Mas onde entra a doxa intelectual nisso tudo? É a partir da ação na mídia que os agentes difusores da problemática do bullying conseguem impô-la como senso comum sobre a violência escolar. A mídia funciona como "lugar neutro", no qual é possível a troca de ideias e de informações nacional e transnacionalmente entre atores sociais dos campos mais diversos. Os colóquios, reuniões e comissões sobre bullying desempenham o mesmo papel. A produção discursiva resultante desses espaços coordena diferentes vozes num discurso científico (médico, psiquiátrico), encobrindo o verdadeiro trabalho de produção simbólica dos lugares-comuns da doxa intelectual. Ademais, são utilizados os "efeitos de intrusão" do campo jornalístico para deslegitimar os agentes mais autônomos, acadêmicos e intelectuais dos campos da Educação e das Ciências Sociais.

O bullying tem toda a aparência de doxa: opera por pares de oposições, sociedade/ indivíduo, nacional/ transnacional, estrutura/ agência, nova temática/ velha temática, e materializa-se em uma vasta literatura, cujo modo de exposição rejeita qualquer tipo de argumentação laboriosa, bem aos moldes do discurso jornalístico.

Destarte, o ato mais importante para essa pesquisa consistiu em investigar relacionalmente dois problemas sociais, demonstrando, portanto, o deslocamento em relação à construção das temáticas no tecido social, passando de um entendimento a outro, ou seja, da violência escolar ao bullying. A noção de doxa intelectual foi importantíssima para trazer à luz parte das estratégias (pelo menos aquelas que passam pelo campo jornalístico) por meio das quais o bullying vem ganhado evidência.

\section{Conclusão}

A exposição acima procurou estabelecer relações entre diferentes textos de inspiração teórica bourdieusiana de modo tal que eles ajudassem a expor os diferentes aspectos do conceito de doxa intelectual. Uma vez que ele (o conceito) se conjuga com estudos que tratam diretamente da análise de campos de produção cultural, ressaltaram-se as contribuições que a noção poderia oferecer ao entendimento das dinâmicas desses campos e, de forma menor, das leis gerais que regem os campos como modelos teóricos que orientam pesquisas específicas. Foi dada prerrogativa 
às dimensões mais gerais, pois deixamos de lado elementos importantes, tais como: uma melhor exploração da relação entre campo e habitus, a illusio, o investimento no jogo, campo como espaço de possíveis etc. Contudo, como qualquer empreendimento do tipo, querer trabalhar um conceito bourdieusiano sem colocá-lo "à prova" parece-nos impossível. Por isso, o texto abunda de exemplos. Trata-se de exemplos franceses para um conceito francês. Utilizamos os campos filosófico, intelectual e literário na medida em que foi por meio da análise desses campos específicos que os pesquisadores acharam necessário designar como doxa intelectual determinada classe de fenômenos que eles observaram em suas pesquisas.

De maneira mais ambiciosa, e talvez um pouco menos evidente, pretendemos demonstrar que o conceito é produto, ele também, das lutas dentro do campo intelectual. No limite, podemos dizer que, como qualquer conceito, ele é um instrumento de luta. E, no caso, a doxa intelectual aparece como uma arma simbólica apontada para os doxósofos em nome de uma visão do que seja um intelectual, objeto maior das lutas dentro desse campo.

No final do texto, procurou-se por "à prova" mais uma vez o conceito, desta feita utilizando-o para explicar o processo pelo qual uma temática ligada à violência escolar foi gradualmente deixando de fazer parte do horizonte de possibilidades explicativas de determinado fenômeno social, sendo substituída por outra, que vem pouco a pouco ganhando centralidade em decorrência da forma pela qual os agentes que a produzem e difundem, devido à sua própria posição, conseguem inscrevê-la na realidade social.

\section{Referências}

Bourdieu, P. (1976). "Le champ scientifique”. Actes de la recherche em Sciences Sociales, n. 2-3, p. 88-104, jun.

. (1984). "Le hit-parade des intellectuels français ou qui sera juge de la légitimité des juges?”. Actes de la recherche em Sciences Sociales. Paris, n.52-53, p. 95-100, jun. Minuit.

(1989). La noblesse d'État: grandes écoles et esprit de corps. Paris, Éditions de

.(1989). “Os doxósofos”. In: Thiollent, M. (Org.). Crítica metodológica, investigação social e enquete operária. São Paulo, Polis.

. (1997). Sobre a televisão. Rio de Janeiro, Jorge Zahar.

.(1998). Contrafogos: táticas para enfrentar a invasão neoliberal. Rio de Janeiro, Jorge Zahar. 
(1999). "Le fonctionnement du champ intellectual". Regards Sociologiques, Paris, n.17-18, p. 5-27.

. (2004). Os usos sociais da ciência - por uma Sociologia clínica do campo científico. São Paulo, Ed. UnEsP.

. (2007). Meditações pascalianas. Rio de Janeiro, Bertrand.

___. (2008). A distinção: crítica social do julgamento. São Paulo, EdusP.

(2010). As regras da arte, gênese e estrutura do campo literário. São Paulo, Companhia das Letras.

Bourdieu, P.; Boltanski, L. (2009). La producción de la ideología dominante. Buenos Aires, Nueva Visión.

Champagne, P. (2007). "L'étude des médias et l'apport de la notion de champ". In: Pinto, E. (Org.). Pour une analyse critique des médias - le débat public en danger. Bellecombe en Bauges, Éditions du Croquant.

DEZAlay, Y.; GARTH, B. (2000). “A dolarização do conhecimento técnico profissional e do Estado: processos transnacionais e questões de legitimação na transformação do Estado, 1960-2000". Revista brasileira de Ciências Sociais, vol. 15, n. 43, p. 163-176.

Halimi, S. (1998). Os novos cães de guarda. Rio de Janeiro, Vozes.

Pinto, L. (1994). "Le journalisme philosophique”. Actes de la recherche en Sciences Sociales, Paris, n. 101-102, p. 25-38, mar.

(2009). Le café du commerce des penseurs: à propos de la doxa intellectuelle. Bellecombe en Bauges, Éditions du Croquant.

SANTOS, J. V. T. (2001). "A violência na escola: conflitualidade social e ações civilizatórias”. Educação e Pesquisa, São Paulo, vol. 27, n. 1, p. 105-122, jan/jun.

SAPIRo, G. (2009) "Modèles d'intervention politique des intellectuels". Actes de la recherche en Sciences Sociales, Paris, n. 176-177, p. 8-31, mar.

ZAluAR, A.; LEAL, M. C. (2001). "Violência extra e intramuros". Revista brasileira de Ciências Sociais, São Paulo, vol. 16. n. 14, p. 145-164.

Recebido em outubro/2011

Aprovado em junho/2012 